\title{
Networking and Collaboration for adoption of innovation and Sustainable Growth: Case Study Evidence from the Small and Medium Enterprises of Khyber Pakhtunkhwa, Pakistan
}

\author{
Dr. MOHAMMAD DAUD ALI \\ Assistant Professor Department of Management Sciences, University of Haripur, Pakistan. \\ Email: dr.daud@uoh.edu.pk \\ Dr. SYED IMAD SHAH \\ Assistant Professor Institute of Management Studies, University of Peshawar, Pakistan. \\ Email: imad_shah@hotmail.com
}

MUHAMMAD ATIQUE RAFIQUE KHATTAK

Lecturer Department of Management Sciences, University of Haripur, Pakistan.

Email: atiqkhattak@hotmail.com

\begin{abstract}
This research is aimed at unraveling the significance of Networking and Collaboration in Pharmaceuticals SMEs of Khyberpakhtunkhwa, Pakistan. The research tried to answer the research problem/question as to whether there is some role of networking and collaboration in the sustainable growth of SMEs through adoption of innovation. The data was collected from eight Pharmaceutical SMEs across two clusters; the Peshawar Cluster and Nowshera clusters in Khyberpakhtunkhwa, Pakistan. A total of 20 interviews were conducted from the respondents where they served with open ended interview protocol once they assented through emails and Telephone. All the respondents/interviewees strongly adhered to the fact that networking and collaboration help in diffusion of innovation and growth of SMEs. Hence there is an enormous evidence of the impact of diffusion of innovation to make the SMEs sustainable and ensure their growth.
\end{abstract}

Keywords: Networking, Collaboration, Innovation Diffusion, Sustainability, SME Growth.

\section{Introduction}

Collaboration and networking are some of the most important remedies to address the ailments and challenges faced by the Small and medium enterprises. In order for SMEs to reach a sustainable growth, SMEs collaborate with one another and with academia. This research is carried out in quest of finding out the implication of networking and collaboration for sustainable SME growth. The main theme of the study is to find how collaboration and networking within industry and across the academia help in spread of innovation. The main themes of the current study are networking, collaboration, sustainability and growth.

\section{Literature Review}

This section is aimed at acquainting the vital themes to the readers. These themes are introduced in light of the extant literature and is not just done in a summarize form rather an organized one. The descriptive themes are discussed in this section and tributes to the scholars are given by citing themselves. 


\section{Networking}

In order to make the businesses more innovative and sustainable, networking is important. The higher the challenges and threats posed to the SMEs, the likely the chance for them to pursue networking. In order to get rid of the external barriers, the horizontal networking play a vital role(Hadjimanolis, 1999 ; Ali \& Shah, 2017).

Although the vitality of networking for idea generations is an accepted fact, the importance of motivated individuals for finding answers to some disparate questions cannot be ignored. In this context customers and firm own personnel are identified to be important. However there are researchers who claim that ideas are seldom generated by the networking of Customers and Personnel, rather innovative ideas are yielded by the overall internal complex processes of the firms and the activities of the competitors (Edvardson et al .2000; Sundbo 1997; Sun, 2011; Subramanian, 1996).

\section{Collaboration}

The scientific inventions of discovery nature are produced by and personified in response to addressing the incentives and special needs of organization in particular vicinities by certain inventors. To understand the diffusion and commercialization of these inventions, the work of some elite scientists has to be kept in focus which is primarily done in universities and are moved to the firms through the collaborations of these scientists on demand(Zucker \& Darby, 1996).

\section{Innovation Diffusion}

Diffusion and spread of innovation of Roger's helps researcher to identify at what rate the Innovation is adopted. In any system where innovation is developed and diffused, there are five categories of people related to Innovation. The first category is of innovators which is $2.5 \%$. Then the early adopters which is $13.5 \%$ whereas early majority and late majority both of which is $34 \%$, whereas the laggards make $16 \%$ of the population (Rogers, 1995).

\section{Methodology}

\section{Methods}

This research is qualitative in nature whereby eight firms from the two clusters of pharmaceuticals were researched in khyberpakhtunkhwa, Pakistan. Interpretivist stands on epistemological paradigm for the purpose of data collection and its subsequent analysis was deemed appropriate as per serving the purpose of the study (Bryman \& Bell, 2007).

Practically stating there are 62 pharmaceuticals firms as per the records of SMEDA and Pakistan Pharmaceutical Association (PPA). The firms are clustered in industrial estate Hayatabad and Nowshera (Cluster \& Godavari, 2011). Since survey and postal distribution of questionnaire is not deemed viable for the lack of response anticipation, the in-person interviews is more appropriate to serve the purpose. In contrast to quantitative research the current study better suits the qualitative research design due to the very nature and assumptions as it is about a particular context (Creswell, 2007; Bryman \& Bell, 2009; Bryman, 1988). Furthermore, the study aims to view the innovation diffusion related event, processes and activities through the eyes of the practitioners/respondents and how it will help them towards sustainable business growth.

This primarily fits in well as qualitative research design (Bryman \& Bell, 2009). The current study relate to the experience and interpretations of the CEO and management in the specific localities where these Pharmaceutical firms are operating. The study qualifies for a qualitative research design as it try to answer 
the How type research questions (Yin, 2009). Case study investigates a contemporary real time issue in a detail manner wherever the boundaries are unclear (Yin, 2003).

The interview protocol comprising of open ended questions were served on the respondents from eight pharmaceutical SMEs in two clusters; Peshawar and Nowshera cluster. In total 20 interviews were conducted from these firms. The researcher tried to collect data from at least two respondents from the same firm. Following a rationale of interviewing the CEO/owner and at least one Manager (either marketing, R\&D or Product) were interviewed so that the data is triangulated and any difference of opinion noted. The interviews were recorded using a recorder and for convenience, the language of interview was kept as per the interviewee choice. These interviews were transcribed verbatim.

\section{Conceptual Framework}

Based on the study of extant literature, the research objective/s and the research question/s a conceptual framework is designed which shows the relationship of each theme towards the other on one hand and guides the researcher to the completion of the research project on the other hand. The framework is given below;

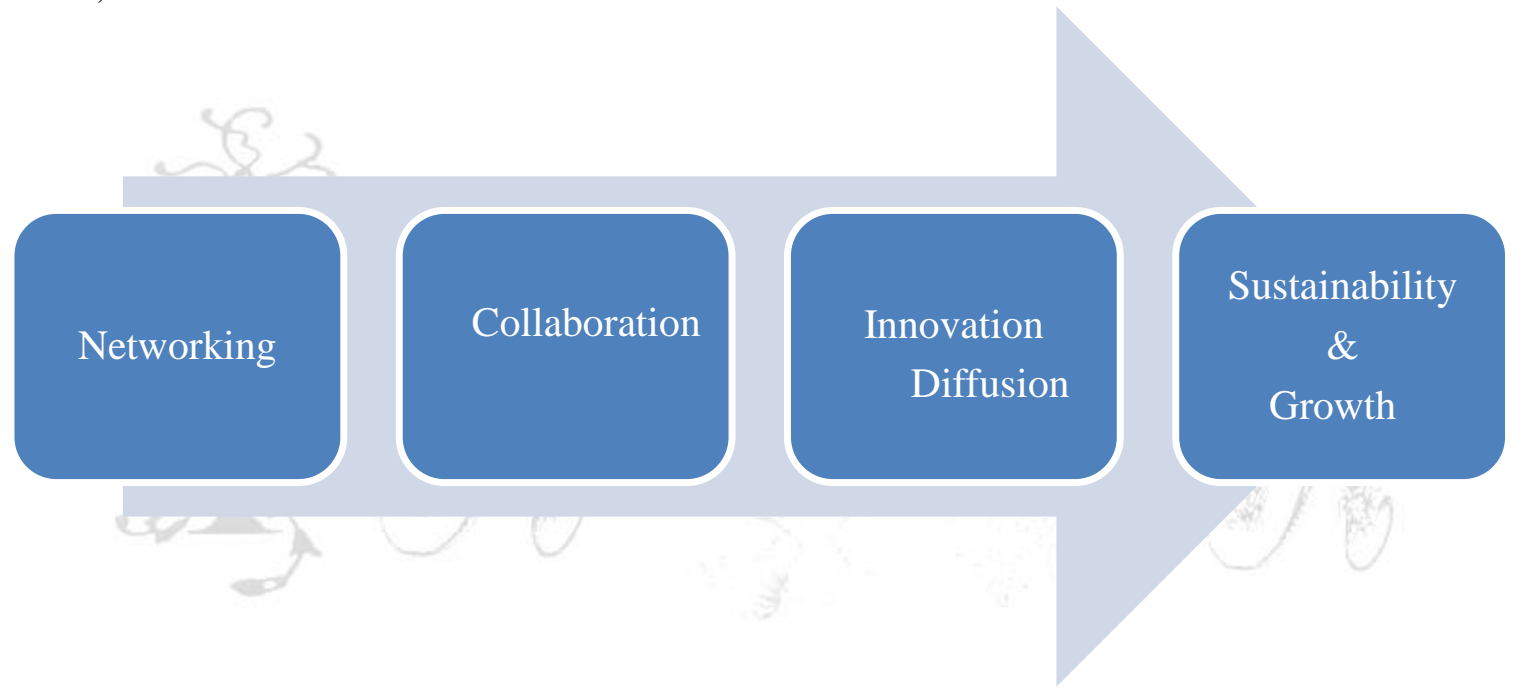

Figure No1: Conceptual Framework

\section{Propositions}

This research work attempts to find answers to the following research propositions:

- Networking and collaboration has a positive role in diffusion of Innovation.

- Diffusion of Innovation contributes towards a sustainable growth of SMEs.

\section{Analysis of Broad themes in case study SMEs}

This study followed a multiple case study method is followed for the data collection as well as its subsequent analysis. The data collected from more than one source offer a complete and rounded analysis while thorough insights are developed too (Hakim \& Catherine, 1987). Studying more cases renders to an enriched analysis as the data is compared contrasted and elaborated simultaneously. 


\section{Networking and Collaboration has positive role in diffusion of Innovation $\left(1^{\text {st }}\right.$ proposition)}

Learning and sharing knowledge is immensely important. By bringing about networking and collaboration for sharing of knowledge, economic sustainability is also ensured (Singe \& Scharmer, 2001). As a whole, the new knowledge creation is rooted in the combination and recombination of knowledge occurring in firms through the interactions of human beings; delving quest for compact sets of facts.

In regard to innovation spillovers, an innovation resulted from the reconfiguration of existing knowledge is only but incremental. In order to move from incremental to somewhat ground breaking disruptive innovation, external networking is a useful ploy (Yang et. al, 2010; Kostov, 2010). Through interactions among internal clusters, the knowledge obtained from external sources is well distributed in SMEs. As the acquisition of more quantifiable and codified knowledge is hard to realize due to the very scientific nature of the knowledge and the lack of potential of the SMEs, these SMEs rely more on the tacit knowledge sources (Bougrain \& Haudeville, 2002).

Behavioral barriers like the top manager's scare of risk and resistance from employees to assent innovation and change are other challenges (Rush \& Beassant, 1992). Although common sense relates barriers of innovation negatively to that of performance of firms, however an interesting interpretation is that if these firms use the barriers as stimuli they can raise the bar of their performance positively. Technological resources are needed from external sources through networking and collaboration to meet the teeming needs of the SMEs. More and more networking is the order of the day to meet SMEs needs. The product manager of one case study SME asserted that sometimes networking and clustering is the resort to cater the lack of technical expertise in own human resources. He was quoted as;

Networking and collaborations can make the production efficient and result into more value added products.

Likewise, lack of expertise is a barrier as per the respondents of rock pharmaceuticals who also seek support in their personal capacity from professional experts working in multinationals. Networking is required to them specifically when they work on creating some new molecules. The researcher found a unanimous agreement among participating SMEs regarding the lack of expertise for innovation as big barrier, but networking and collaboration is established as remedy. Innovation is triggered when technical knowledge is aimed through networking and collaboration.

On the more pragmatic front, the developed world's SMEs have learnt the art of innovation more as compared to the developing world. There are national and regional Innovation system which helps in conquering over the obstacles faced by the SMEs for their innovation adoption and diffusion; resultantly improving the economies. Due to its immense importance, an entirely experienced and skilled team from across the government sector and inventors may be involved to draw a roadmap for innovative production and subsequent growth of SMEs(Yao, 2008).

\section{Diffusion of Innovation contributes towards a sustainable growth of SMEs( $2^{\text {nd }}$ Proposition)}

By and large it is presumed that entrepreneurship associates to innovation, flexibility and growth (Drucker, 1985; Backman, 1983; Birch, 1987). It is imperative for Small businesses to internationalize in order to get pace with the speedy globalization. Hence being more entrepreneurial in their behavior may in turn help in adoption and diffusion innovation. Although it is hard to gauge the empirical effect of innovation on the overall effectiveness of firms but it is believed that innovation has substantial impact on performance. The more is invested in R\&D, the more will it guarantee an edge over competitors (Vollenhoven \& Buys, 2010). From the empirical outcomes, one can derive the conclusion that those firms which remain innovative for longer, a persistently sustainable and innovative organization with persistently competitive advantage can prevail (Le Bas \& Scellato, 2014). More persistently innovative firms not just leave its mark 
on the strategic management but on innovative economic and public policy. The persistence in firms substantiate the Endogenous Growth Theory which suggest that firm become persistent enough to contribute towards economic stability only once it attains knowledge of technology (Romer, 1990). The theory of strategic management also views persistent innovation loop as something resulting in an interfirm sustainability beside the competitive advantage of firms (Ganter \& Hecker, 2013). The rate at which innovation is diffused defines firm's destiny towards their future performance (Banbury \& Mitchell, 1995; Damanpour, 1991). An increased overall efficiency in processes, production and service delivery enables the firms to meet market demands and expand themselves for other new markets (Brown \& Eisenhardt, 1995; Burgelman, 1991).

Permanently changing environmental conditions is a unique challenge that consistently forces the entrepreneurs to ponder on ways and means as to how they can overcome their rival SMEs in regard to their competitive advantage in knowledge based economy (Damanpour \& Evan, 1984). An SME which focuses on technological innovation endures more chances for their survival; bringing new technologies and doing things through newer methods warrants competitive advantage (Porter, 1990). Innovation as compared to invention is characterized by the fact that innovation is practically applicable and hence it contributes to the performance of firms (Schuetze \& Gibson, 1997; Cooper, 1998).

All the participating SMEs adhered to the fact that innovation plays an important role in the performance and sustainable growth of the firm. In the first interview, respondents from Hizat pharmaceutical linked its significance to the amount of competitive advantage it conveys to the firm which in turn increases the market share. Wisdom pharmaceutical contemplate adoption and diffusion of innovation essential as it enhances the overall firm performance granting an improvised profits and market shares due to the uniqueness brought by innovation to its product line. Another case study firm, Zinta pharmaceutical also regarded adoption and diffusion of innovation for sustainable organizational growth. Similarly, Aries pharmaceutical too propose that since adopting innovation expands market stakes, it surges the growth of the firm. The respondents from Stanley added categorically that growth is the aim of SMEs that is why they adopt innovation. Delta pharmaceutical went extra yards by strongly emphasizing that not just growth but even the very survival of SMEs is due to its adoption of innovation. The Iceberg pharmaceutical respondents asserted that since innovativeness means having competitive edge, which is why firm's growth is ensured. Likewise, Rock pharmaceutical too established the fact that innovation gives firm competitive advantage over competitors. So the researcher observed strong agreement among the respondents of all the eight participant firms about the prominence of innovation by SMEs for growth. Accordingly, all the cases strongly agreed that the adoption of innovation is important for organization sustainability and is positively associated to growth.

\section{Discussion and Conclusion}

The conclusions are drawn for propositions and a link is established between networking and collaboration and the role it plays for the adoption of innovation and growth of SMEs in Khyber-Pakhtunkhwa, Pakistan. The more entrepreneurial firms stand with more chances to adopt and diffuse innovation. The networking and collaboration largely depends on what industry is researched. For the pharmaceutical industry, an industry which is science and knowledge based, networking and collaboration with industry as well as academic is easy to manipulate. The degree at which the case study SMEs accepts the change and innovations varies from industry to industry and from firm to firm. Even in some of the case study SMEs, some departments are more adoptive than other. This situation is supported by the literature as Griffin (1997) views different contexts requiring different processes which entail innovations of more robust nature.

From the researcher observation and participant's narration, it can be concluded that those firms which were entrepreneurial by nature were more open to accept change and innovation as compare to the rigid and 
inertial type of firms. This results in improved overall performance of the firms and tenders sustainable growth

\section{References}

Ali, M. D., \& Shah, S. I. (2017). The Challenges to the Diffusion of Innovation in Small and Medium Enterprises in Khyber Pakhtunkhwa Pakistan. Journal of Managerial Sciences, XI(03).

Banbury, C. M., \& Mitchell, W. (1995). The effect of introducing important incremental innovations on market share and business survival. Strategic management journal, 16(S1), 161-182.

Bougrain, F., \& Haudeville, B. (2002). Innovation, collaboration and SMEs internal research capacities. Research policy, 31(5), 735-747.

Bryman, B. and Bell, E. (2007) Business Research Methods, 2nd ed., Oxford: Oxford University Press

Burgelman, R. A. (1991). Intraorganizational ecology of strategy making and organizational adaptation: Theory and field research. Organization science, 2(3), 239-262.

Cluster, R. M., \& Godavari, W. (2011). Cluster Profile, (July), 4-5.

Cooper, J. R. (1998). A multidimensional approach to the adoption of innovation. Management decision.

Creswell, J. W. (2007). Chapter 3: Designing a Qualitative Study. Qualitative Inquiry and Research Design: Choosing among Five Approaches, 35-41.

Damanpour, F., \& Evan, W. M. (1984). Organizational innovation and performance: the problem of" organizational lag". Administrative science quarterly, 392-409.

Damanpour, F., Walker, R. M., \& Avellaneda, C. N. (2009). Combinative effects of innovation types and organizational Performance: A longitudinal study of service organizations. Journal of Management Studies, 46(4), 650-675

Edvardsson, B., Gustafsson, A., Sandén, B., \& Johnson, M. D. (2000). New Service Development and Innovation in the New Economy. Lund: Studenlitteratur

Eisenhardt, K. M. (1989). Building Theories from Case Study Research. Academy of Management Review, 14(4), 532-550.

Ganter, A., \& Hecker, A. (2013). Persistence of innovation: Discriminating between types of innovation and sources of state dependence. Research Policy, 42(8), 1431-1445.

Griffin, A. (1997). The effect of project and process characteristics on product development cycle time. Journal of marketing research,34(1), 24-35.

Hadjimanolis, A. (1999). Barriers to innovation for SMEs in a small less developed country (Cyprus). Technovation, 19(9), 561-570.

Hakim, Catherine (1987) Research design: strategies and choices in the design of social research. Contemporary Social Research Series. (13). Allen and Unwin, London, UK

Le Bas, C., \& Scellato, G. (2014). Firm innovation persistence: a fresh look at the frameworks of analysis.

Porter, M. E. (1990). The competitive advantage of nations. Harvard business review, 68(2), 73-93.

Read, A. (2000). Determinants of successful organisational innovation: a review of current research. Journal of management practice, 3(1), 95-119.

Rogers, E. M. (1995). Diffusion of innovations. New York: Free Press.

Romer, P. M. (1990). Endogenous technological change. Journal of political Economy, 98(5, Part 2), S71S102.

Scharmer, C.. (2001). Self-transcending knowledge: Sensing and organizing around emerging opportunities. Journal of Knowledge Management. 5. 137-151.

Subramanian, A., \& Nilakanta, S. (1996). Organizational innovativeness: Exploring the relationship between organizational determinants of innovation, types of innovations, and measures of organizational performance. Omega, 24(6), 631-647.

Sun, S. (2011). Innovation Mode and Strategy Research on Small and Medium-sized Enterprise Emarketing in Post Financing Crisis, 4, 13-18

Sundbo, J. (1997) Management of Innovation in Services. Service Industries Journal, 17, 432-455. 
van Vollenhoven, B. G., \& Buys, A. J. (2010, July). The importance of innovation for firm performance in the automotive component manufacturing industry in South Africa. In Picmet 2010 Technology Management For Global Economic Growth (pp. 1-7). IEEE.

Yao, J. (2008). Techonological Innovation Management of Chinese Small and Medium Enterprises. 2008 International Seminar on Business and Information Management, 413-416.

Yin, R.K. (2009) Case Study Research: Design and Methods, 4th, ed. London: Sage

Zucker, L. G., \& Darby, M. R. (1996). Star scientists and institutional transformation: patterns of invention and innovation in the formation of the biotechnology industry. Proceedings of the National Academy of Sciences of the United States of America, 93(23), 12709-12716.
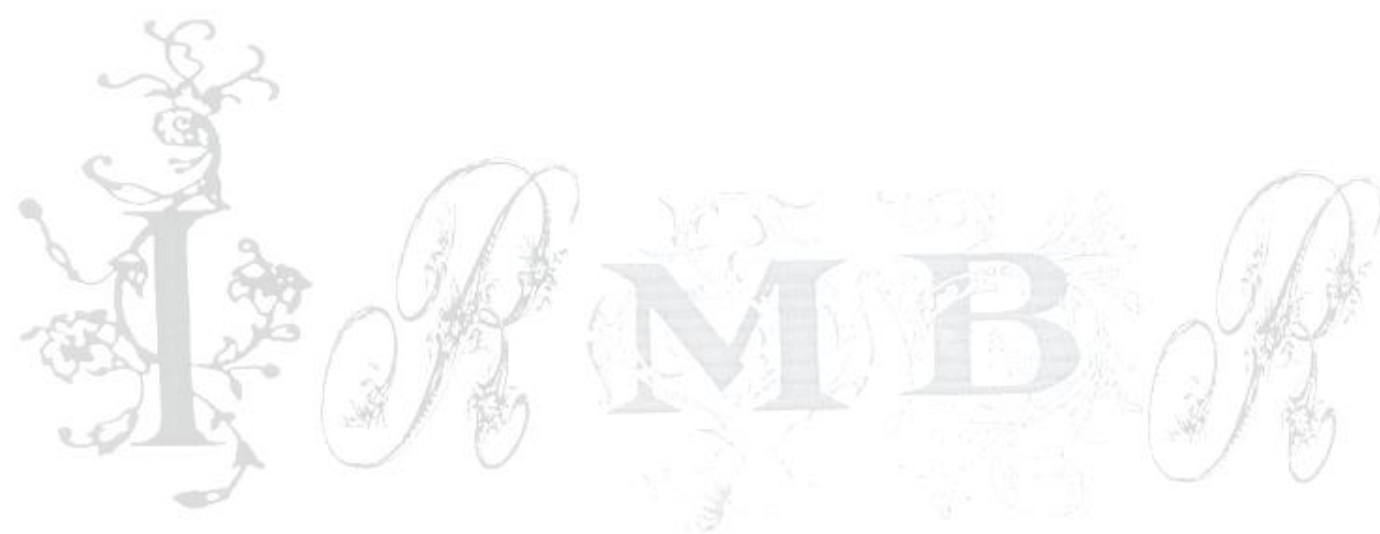